Oscar Winberg

\section{ARCHIE BUNKER JA KONSERVATISMI SARJASSA PERHE ON PAHIN}

Perhe on pahin -sarjan päähenkilöstä Archie Bunkerista tuli poliittinen ikoni ja konservatiivisuuden edustaja 1970-luvun alun Yhdysvalloissa. Tässä artikkelissa tarkastellaan politiikkaa 1960-jälkipuoliskon televisiossa ja osoitetaan, että Archie Bunkerin poliittiset mielipiteet ovat liian ambivalentteja tullakseen ymmärretyiksi yksiselitteisesti konservatiivisuutena. Sen sijaan Richard Nixonin yritykset vähentää talouspolitiikan painoarvoa julkisessa keskustelussa ja luoda näin konservatiivinen enemmistö selittävät Bunkerin mieltymistä uuden konservatiivisen enemmistön ruumiillistumaksi.

Graffiti julisti New Yorkin maanalaisessa 1970-luvun alussa: "Archie Bunker for President". Seinäkirjoitus tiivistää, kuinka nopeasti uuden satiirisen tilannekomedian Perhe on Pahin (All in the Family, CBS 1971-1979) päähenkilö Archie Bunkerista (Carroll O'Connor) oli muodostunut poliittinen ikoni. Graffiti saattoi olla satiirinen tai sitten graffititaiteilija kuului suureen joukkoon amerikkalaisia, joille Archie oli poliittinen liittolainen, joka puhui jokamiehen suulla. Joka tapauksessa ei kulunut aikaakaan, kun joku toinen teki kirjoitukseen lisäyksen: "He is" - hänhän on presidentti (Castleman \& Podrazik 2010, 211). Ilmaisukyvyltään rajoittuneen kiihkoilija Archien ja presidentti Richard Nixonin suora rinnastaminen on ehkä epäreilua, mutta on kuitenkin selvää, että Archie alettiin pian ymmärtää yhteydessä Nixonin näkemykseen konservatiivisuudesta. Itse asiassa hänet alettiin nähdä ja hyväksyä 1970-luvun alun konservatiivisen vastaliikkeen personifikaatioksi - vastaliikkeen, jota Nixon nimitti "hiljaiseksi enemmistöksi" (silent majority) (Nixon 1969).

Tarkastelen tässä artikkelissa, miten Archie Bunkerin hahmosta muodostui yksi parhaiten tunnetuista "uuden konservatiivisen enemmistön" (the New Right) ja "hiljaisen enemmistön" edustajista. Ilmiön ymmärtäminen edellyttää Perhe on pahin -sarjan analyysia amerikkalaisen tilannekomedian, televisiopolitiikan ja laajemmin USA:n konservatismin kehyksissä. Miten Perhe on pahin -sarjasta tuli 1970-luvun alun poliittisin fiktiivinen viihdeohjelma ja miten kriitikot, tekijät ja yleisö ilmaisivat näkemyksensä Archie Bunkerista konservatiivina Nixonin kauden poliittisessa ilmapiirissä?

Perhe on pahin -sarjan ensimmäinen jakso lähetettiin tammikuussa 1971. Sarjaa esitettiin yhdeksän tuotantokauden ajan vuoteen 1979 asti. Tässä ar-
Oscar Winberg, FM

Historia, Åbo Akademi

Tekstin kääntänyt englannista suomeksi Rami Mähkä

\footnotetext{
Sarjaa esitettin yhdeksän tuotantokauden ajan vuoteen 1979 asti. Tässä ar-
} 


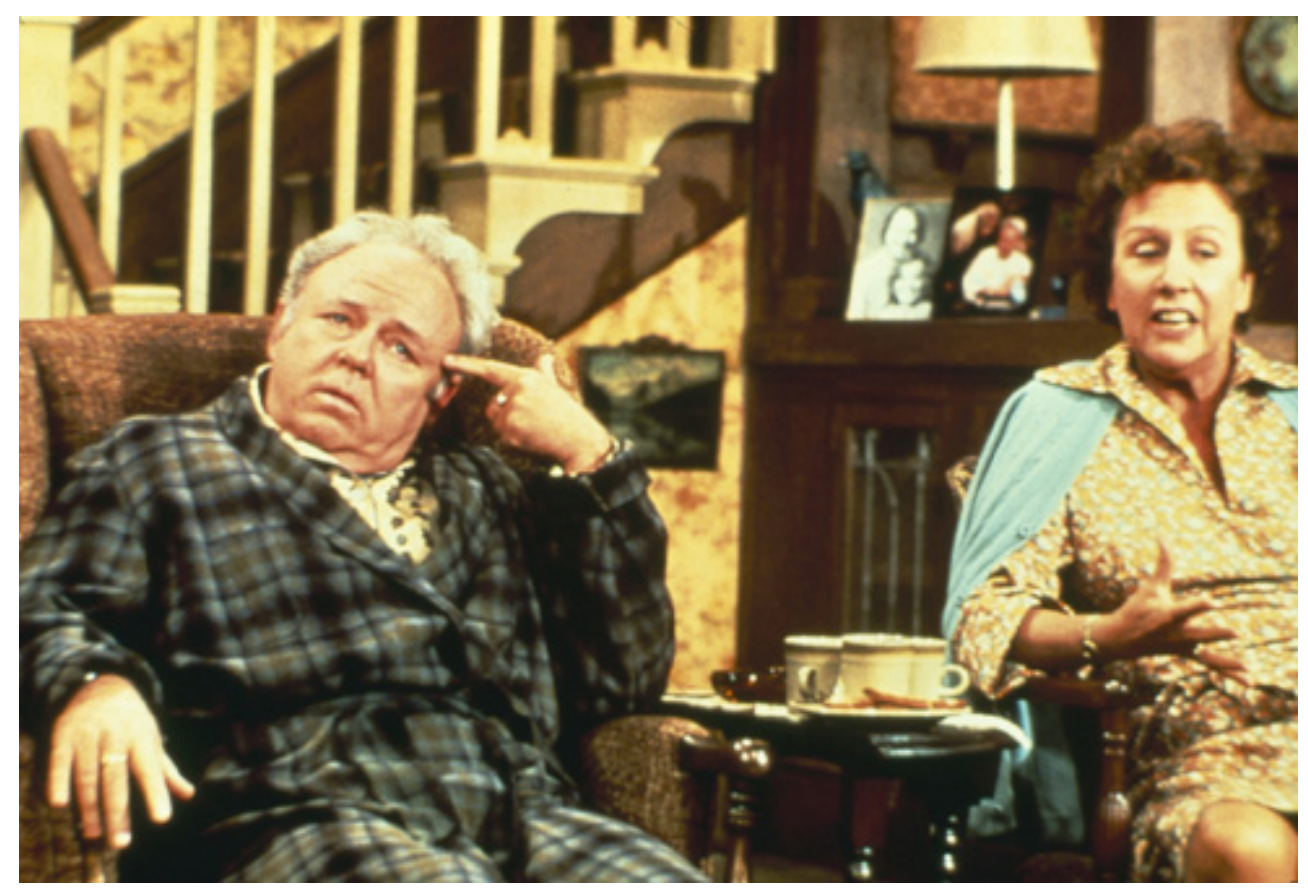

Perhe on pahin -sarjan Archie Bunker (Carroll O'Connor) alettiin pian sarjan alettua nähdä "uuden konservatiisen enemmistön" ilmentymänä 1970-luvun USA:ssa. Rouva Edith Bunkerin (Jean Stapleton) poliittiset mielipiteet olivat yleensä miestään joustavampia. Kuva: Nelonen.

tikkelissa tarkastelen kuitenkin vain neljää ensimmäistä tuotantokautta, sillä keskityn Nixonin kauteen, joka päättyi presidentin eroon elokuussa 1974. Kuten edellä todettiin, keskeistä artikkelissa on Nixonin ajan konservatiivisen enemmistön nousu. Lähestyn ilmiötä mainitun ajanjakson poliittisessa ja kulttuurisessa kontekstissa. Metodologisesti artikkeli perustuu kontekstualisoivalle lähiluvulle, jossa keskeistä on audiovisuaalisen tekstin ideologisuus. Teksti ymmärretään artikkelissa laajasti esimerkiksi televisio-ohjelmina (Fiske 1987, 14). Kontekstualisoiva metodi mahdollistaa tilannekomedian sisältöanalyysia laajemman kulttuurisen ja yhteiskunnallisen analyysin, jossa huomioidaan televisioteollisuuden käytänteet, kritiikki ja erilaiset julkiset ja poliittiset diskurssit. Koska analysoin ajatusta Archie Bunkerista konservatiivisen vastaliikkeen personifikaationa, tarkastelussa ovat hahmolle annetut poliittiset merkitykset, joihin vaikuttavat itse sarja televisiotekstinä ja aikakauden poliittinen konteksti.

\section{Konservatismin tutkimus ja televisioviihde}

Historioitsija Alan Brinkley kirjoitti vuonna 1994 The American Historical Review -lehdessä, että konservatismilla on orpolapsen asema historiantutkimuksessa (Brinkley 1994, 409). Kirjoitus toimi sysäyksenä konservatismin tutkimuksen huomattavalle nousulle Yhdysvalloissa. Viimeaikaisen tutkimuksen mukaan niin sanotussa konservatiivisessa vastaliikkeessä ei ollut niinkään kyse uuden konservatiivisuuden nousemisesta 1960-luvun liberalismin vastavoimaksi kuin pikemminkin konservatismin paluusta pitkän "liberaalin poikkeaman" 
jälkeen (Durr 2003, 2; Cowie \& Salvatore 2008, 4-5). Itse asiassa ilmiöön liitetty termi vastaliike (backlash) on niin ikään kyseenalaistettu, kun silloiseen konservatismin nousuun yhdistetyillä asioilla ja ilmiöillä on osoitettu olevan pidempi historiallinen tausta; konservatismin nousu ulottuu kauemmas kuin vain 1960-luvun jälkipuoliskon yhteiskunnallisiin levottomuuksiin ja niiden herättämiin reaktioihin (Phillips-Fein 2011, 727-728).

Konservatismin nousua on tarkasteltu useammasta historiallisesta näkökulmasta. Näkökulmien erottelu auttaa keskeisellä tavalla ymmärtämään, miten Perhe on pahin ja erityisesti Archie nähtiin poliittisesti aikakauden amerikkalaisessa poliittis-yhteiskunnallisessa kontekstissa. Sekä Jefferson Cowie että Penny Lewis problematisoivat näkemyksen työväenluokasta sotaa kannattavana, poliittisella kartalla oikealle liikkuvana monoliittina ja painottavat työväenliikkeen ja ammattiyhdistysten sisäisiä ristiriitoja ja konflikteja (Cowie 2010; Lewis 2013). Vastaavasti Dan T. Carter on osoittanut, miten rotukysymykset ja talouspolitiikka osaltaan vaikuttivat konservatiivisuuden vahvistumiseen 1970-luvulla (Carter 1999; Carter 2000). Talouspolitiikan ja liike-elämän roolin merkitystä ovat puolestaan korostaneet Kim Phillips-Fein ja Judith Stein (Phillips-Fein 2010, Stein 2010). 1970-luvun konservatiivisen vastareaktion historiallista jännettä, jota myös joskus luonnehditaan vastavallankumoukseksi tai, kuten edellä totesin, konservatiiviseksi enemmistöksi, on selitetty sosiaali- ja poliittisten historioiden sekä urbaani- ja intellektuaalisten virtausten tutkimuksen näkökulmista (Lassiter 2007; McGirr 2015; Kruse 2007; Kruse 2015; Self 2013; Schulman \& Zelizer 2008; Burns 2009; Hartman 2015).

Tutkimusta konservatismin paluusta on siis tehty paljon ja varsin kattavasti. Sillä on kuitenkin puutteensa. Konservatismin historiallisen tutkimuksen tilannetta kartoittavassa perinpohjaisessa artikkelissaan Phillips-Fein peräänkuuluttaa massamedian merkityksen tutkimusta (Phillips-Fein 2010). Vaikka Phillips-Fein viittaa ensi sijassa ei-fiktiiviseen massamediaan, voidaan todeta, että fiktiivisen ja viihteellisen median osalta tutkimuksen tarve on vieläkin suurempi. Itse asiassa konservatismin ja televisioviihteen suhteita tarkastelevaa tutkimusta on tehty yllättävän vähän. Tärkein Perhe on pahin -sarjan tieteellinen analyysi käsittelee sitä 1960-luvun kulttuurisen vallankumouksen kontekstissa (von Hodenberg 2015). Tutkimus liittyy trendiin tarkastella ideologiaa mediassa, kuten televisioviihteessä, kulttuurisen pikemminkin kuin poliittisen tasolla (Hamamoto 1991, Ozersky 2003, Greene 2007). Tämä artikkeli täyttää osaltaan aukkoja konservatiivisuuden ja televisioviihteen tutkimuksessa.

Kun arvioidaan, onko Archie Bunker konservatismin edustaja vai ei, on pohdittava modernin konservatismin ymmärtämistä Yhdysvalloissa yleisellä tasolla. On huomattava, että pelkästään sodanjälkeisen amerikkalaisen konservatismin tarkka määrittely on miltei mahdoton tehtävä. Esitän tässä artikkelin kysymyksenasettelun kannalta keskeisiä määrittelyitä ja näkökulmia konservatismille. Konservatiivi-intellektuelli Russell Kirk julistaa, että konservatismi ei ole mikään määrätty muuttumaton dogmi (Kirk 2001, 7-8), kun taas historioitsija George Nash pitää ajatusta konservatismin tarkasta määrittelystä jo ajatuksen tasolla harhautuneena. Sen sijaan konservatismi pitäisi nähdä kolmen intellektuaalisen virtauksen eli libertarismin, traditionalismin ja antikommunismin yhteenliittymänä (Nash 1996, xiii-xvi). Kirkin mielestä libertarismi on konservatiivisuuden vastakohta (Kirk 1981, 351). Johtavan konservatiivi-intellektuelli William F. Buckleyn määritelmässä puolestaan konservatismissa korostuu antikommunismin ja traditionalismin ohella libertarianismi (Buckley 1955, 6). Esimerkkien kautta on helppo ymmärtää, miksi 
konservatismin määrittelyn epäonnistumisen perustana pidetään yrityksiä hahmottaa konservatismi homogeenisenä monoliittina (Schoenwald 2002, 4-5; Bowen 2011, 76).

Archie Bunkerin hahmon konservatismin tulkitsemisen näkökulmasta on syytä nostaa esiin vielä Phillips-Feinin konservatismin historiallinen määritelmä, jossa on keskeistä historiallisuuden ajatuksen korostaminen ideologisfilosofisen näkökulman sijaan. Hänen mukaansa moderni amerikkalainen konservatismi on historiallisesti keskittynyt antikommunismin, laissezfaire-talousajattelun, kansalaisoikeusliikkeen vastustamisen ja "perinteisten seksuaalinormien" ympärille (Phillips-Fein 2011, 727). Nämä neljä ideologista virtausta ovat keskeiset tämän artikkelin modernin amerikkalaisen konservatismin määritelmälle. Poliittisen historian ja korporatiivisen ideologisen vaikuttamisen tasojen ohella otan Phillips-Feinin mallin esittämällä tavalla huomioon ruohonjuuritason ja tarkastelen konservatismia elettyinä kokemuksina. Tämä on tarpeen jo siksi, että tarkastelun keskiössä ovat tavallisia ihmisiä edustavat henkilöhahmot. Phillips-Fein ei nosta konservatismin ja uskonnon yhteyttä esiin vain perinteisten seksuaalinormien kohdalla, vaan uskonnollinen oikeisto arvoineen on sisällytettynä kaikissa neljässä mainitussa konservatismin piirteessä. Esimerkiksi Archie Bunker, joka on protestantti, on ambivalentti uskovaisuutensa suhteen. Hän käyttää Raamattua argumenttiensa perustana mutta ei osoita syvempää henkilökohtaista vakaumusta eikä läheistä yhteenkuuluvuutta kirkon kanssa.

\section{0-luvun jälkipuoliskon televisiopolitiikat}

Yhdysvaltojen televisio poikkeaa julkisen palvelun järjestelmään pohjautuvien maiden televisiosta siinä, että sen sisältöä ohjaavat ensi sijassa kaupalliset tavoitteet eli taloudellisen kannattavuuden vaatimukset. Amerikkalaisten televisio-ohjelmien tuottavuus on aina perustunut mainostajien kiinnostukselle, joka puolestaan pohjautuu ohjelman saamiin katsojalukuihin (Staiger 2000, 104-105). Tässä ansaintalogiikassa kaikkein houkuttelevin ohjelma televisiokanavalle onkin teoriassa sellainen, joka ei ärsytä ketään katsojista (Berkowitz 2006, 198). Käytännössä periaate johti NBC:n Paul L. Kleinin LOPteoriaksi kutsumaan kiteytykseen: "Least Objectionable Program". Ideana oli, että katsojat seuraavat prime time -televisiota riippumatta siitä, mitä esitetään - ja he valitsevat tällöin vähiten ärsyttävän ohjelman. (Edgerton 2007, 244.) Ohjelmat tulikin suunnata mahdollisimman laajalle yleisölle välttäen arkaluontoisia aiheita ja suosien konsensukseen tähtääviä narratiiveja (Adler 1979, xvi; Ozersky 2003, 64).

Kun 1960-luvun lopulla tarvittiin entistä tarkempia kohderyhmätietoja mainosteollisuuden käyttöön, A.C. Nielsen Company kehitti edelleen katsojatietoja mittaavaa järjestelmäänsä sisällyttäen siihen demografista dataa (Mittell 2010, 82). Tämä auttoi mainostajia löytämään kiinnostavat kohderyhmät. Pelkät katsojamäärät eivät siis enää automaattisesti muuntuneet tuottavuudeksi (Ozersky 2003, 44-45). Muutos merkitsi loppua Kleinin LOP- ja konsensusideoille sekä CBS:n menestyksen takana olleille maalais-sitcomeille. 1960-luvun suurimpia katsojalukuja keränneet sarjat, kuten The Beverly Hillbillies (CBS, 1962-1971), Green Acres (CBS, 1965-1971) ja Petticoat Junction (CBS, 1963-1970), olivat perustuneet maalaiselle identiteetille ja keränneet suuren mutta kaupallisesti epäkiinnostavan yleisön (Adler 1979, xviii). Maalaiskomedioiden 
yleisöt olivat mainostajien silmissä vähiten kiinnostavia: vanhoja, maalaisia ja huonommin toimeentulevia (Castleman \& Podrazik 2010, 209).

Televisiojohtajia ei toisaalta kiinnostanut 1960-luvun vastakulttuurikaan, vaan he olivat keskittyneet konsensus-henkiseen viihteeseen (Marc 1996, 46). Konsensus-narratiivit toimivat eräänlaisena psykologisena eskapismina ("psychological refuge") 1960-luvun poliittiselle ja yhteiskunnalliselle kuohunnalle (Barnouw 1990, 401). Perhe on pahin -sarjan luoja Norman Lear on kiteyttänyt asian seuraavasti:

For twenty years - until [All in the Family] came along - TV comedy was telling us there was no hunger in America, we had no racial discrimination, there was no unemployment or inflation, no war, no drugs, and the citizenry was happy with whomever happened to be in the White House. (Lear 2014, 266-267).

Tärkeimpiä kohderyhmiä tavoitellessaan CBS:1lä näytti olevan varaa ottaa riskejä - olihan se hallinnut katsojatilastoja vuosikymmeniä. Todellisuudessa riskinottoon loi painetta se, että CBS voitti vain niukasti kilpailijansa NBC:n kaudella 1969-1970 (Castleman \& Podrazik 2010, 209). ${ }^{1}$ Kuten suuryrityksissä yleensäkin, televisiojohtajat olivat tyypillisesti poliittisesti konservatiivisia eikä CBS:n perustaja ja puheenjohtaja William Paley ollut poikkeus (Ozersky 2003, 37). Hän oli skeptinen uusien mittausmenetelmien ja televisioyhtiön presidentti Robert Woodin ja tämän luottomiehen Fred Silvermanin ehdotuksille uudesta, ajankohtaisesta ja provosoivasta ohjelmasisällöstä (Ozersky 2003, 46). Lopulta Paley kuitenkin myöntyi, kun hänet haastettiin johtamaan television uudistumista ja keräämään uusia taloudellisia voittoja (Campbell 2007, 8).

On syytä painottaa, että suurten televisioyhtiöiden johtoporras oli hyvin tietoinen television erittäin näkyvästä roolista yhteiskunnassa sekä siitä johtuvista - tosin vaihtelevista - poliittisista yrityksistä kontrolloida televisiota (Castleman \& Podrazik 2010, 207). 1960-luvun lopun yhteiskunnallinen tilanne näkyi myös televisiota kohtaan kohdistettuna paineena. Television esittämää väkivaltaa vastaan kampanjoitiin senaattoritasolla, ja Vietnamin sodan esittäminen televisiossa sai osakseen poliittista kritiikkiä (Ozersky 2003, 38; Castleman \& Podrazik 2010, 212-213). Suorimman hyökkäyksen televisioyhtiöiden johtoa kohtaan teki Nixonin varapresidentti Spiro T. Agnew marraskuussa 1969, kun hän viittasi pienen "etuoikeutetun veljeskunnan" ("a tiny enclosed fraternity of priviliged men") suuren vaikutusvaltaan television välityksellä. Vaikka hyökkäys kohdistui television uutistoimituksiin, se oli varoitus televisioyhtiöille yleisemminkin. (Barnouw 1990, 443.) On muistettava, että televisioyhtiöt olivat haavoittuvia mahdollisille poliittisille sanktioille, sillä niiden monopoli (ABC, CBS, NBC) perustui hallituksen lisensoinnille (Ozersky 2003, 54, 58). ${ }^{2}$

Edellä kuvatussa poliittisessa ilmapiirissä komedialle muodostui erityisasema. 1960-luvun lopun uudet varieteeshow't The Smothers Brothers Comedy Hour (CBS, 1967-1969) ja erityisesti Rowan and Martin's Laugh-In (NBC, 1968-1973) osoittivat, että samanaikainen "oikeiden" katsojaryhmien ja suurten katsojalukujen tavoittaminen oli mahdollista. Sarjat sisälsivät poliittista komediaa, mutta niiden suosio laski huomattavasti 1970-luvulla. Sen sijaan toinen televisiokomedian laji, tilannekomedia politisoitui huomattavasti 1970-luvun kuluessa. Tämän teki televisiopolitiikan kannalta mahdolliseksi itse asiassa se, että, kuten Mulkey esittää, fiktiivisyyden ohella komediallisuus laimentaa minkä tahansa poliittisen kommentaarin. Tämä koskee erityisesti tilannekomediaa (Mulkay 1988, 5). Perhe on pahin syntyi siis yhteiskunnallisen tilanteen,
1 Tuotantokausi käsittää USA:n televisiossa ajanjakson syyskuu-huhtikuu. Kesäkuukausina esitetään uusintoja. NBC:n Paul Klein väitti, että CBS ei itse asiassa voittanut kautta 1969-1970 painottaen täten katsojaprofiilin olevan pelkkiä katsojamääriä tärkeämpi kriteeri (Edgerton 2007, 274).

2 Esimerkkinä siitä, kuinka paljon monopoli merkitsi televisioyhtiöille taloudellisesti: kongressi kielsi tupakkamainonnan televisiossa keväällä 1970, mikä aiheutti televisioyhtiöille 200 miljoonan dollarin vuosittaisen tulonmenetyksen (Ozersky 2003, 58). 
poliittisen ilmapiirin, korporaatioihin kohdistettujen haasteiden ja komedian tarjoamien kaupallis-sisällöllisten mahdollisuuksien yhteisvaikutuksesta.

\section{Television katsotuin ohjelma}

Siitä asti, kun elokuvantekijä Norman Lear oli lukenut BBC:n sarjasta Till Death Us Do Part (BBC, 1965-1975), hän halusi tehdä siitä työtoverinsa Bud Yorkinin kanssa adaptaation Yhdysvaltain televisioon (Adler 1979, xix-xx). Kaksikko tarjosi pilottia $\mathrm{ABC}$ :lle tässä vaiheessa vielä nimellä And Justice for All, mutta kiistanalainen sisältö johti kielteiseen päätökseen. Muista yhtiöistä CBS:n Fred Silverman näki pilotissa potentiaalia, sillä se vastasi hänen ja Woodin uudistetun ohjelmiston tarpeita: ohjelman idea oli uskottava, ajankohtainen ja ennen kaikkea toivotulle kohderyhmälle sopiva (Gitlin 2000, 36). Sen sijaan Paley oli varsin ennalta-arvattavasti skeptinen niin sarjan yleistä kiistanalaista luonnetta kuin sen osoittamia poliittisia sympatioitakin kohtaan (Lear 2014, 236). Varotoimenpiteenä Wood sijoitti sarjan alkamaan kesken tuotantovuoden tammikuussa 1971. CBS myös varoitti katsojia etukäteen ilmoittamalla, että Perhe on pahin -sarjan ideana on esittää ihmisten heikkoudet, ennakkoluulot ja huolenaiheet humoristisessa valossa (Lear 2014, 238). Aluksi odotettua katsojareaktiota ei tullut, vaikka kriitikotkin uskoivat sarjasta tulevan seuraavan päivän puheenaihe työpaikoilla (Castleman \& Podrazik 2010, 220-221). Kun toista tuotantokautta oli syyskuussa 1971 esitetty kaksi viikkoa, sarja oli kuitenkin katsojalukujen kärkisijalla. Se myös onnistui pitämään sijoituksensa viisi vuotta. Kymmenet miljoonat amerikkalaiset katsoivat viikoittain Archie Bunkerin ja hänen perheensä kinastelua.

Perhe on pahin -sarjassa seurataan Edith (Jean Stapleton) ja Archie Bunkerin, heidän tyttärensä Glorian (Sally Struthers) ja vävynsä Mike Stivicin (Rob Reiner) elämää. Mike viimeistelee opintojaan. Vastanainut nuoripari asuu Glorian kotona, joka on loputtomien poliittisten kiistojen tapahtumapaikka. Archie on ennakkoluuloinen kiihkoilija, joka työskentelee työnjohtajana rekkojen lastausalueella, kun taas Gloria ja Mike ovat vastakulttuuria edustavia liberaaleja. Naiivi Edith toimii sarjassa omatunnon äänenä, hän on poliittisilta mielipiteiltään joustava. Jaksojen tarinat käsittelevät säännöllisesti ajankohtaisia ja kiistanalaisia aiheita, kuten rotuerottelua, homoseksuaalisuutta, naisten oikeuksia, kansalaisoikeuksia ja Vietnamin sotaa. Koska tuottajat ja näyttelijät olivat itse liberaaleja, he esittävät Archien narrina ja hänen mielipiteensä intellektuaalisesti onttoina. Bunkerin sivistymättömyyttä korostetaan toistuvilla malapropismeilla ("ivory shower", "albacross around my neck", "minororities" jne.). Koomista efektiä lisätään naururaidalla ja pitkillä reaktiootoksilla Archien kasvoista, kun joku on nöyryyttänyt häntä verbaalisesti (Rosa \& Eschholz 1972, 278). Sarjan luoja Lear itse totesi, että Bunkerilla on usein tapana kehitellä jokin kieroutunut logiikka argumenttinsa tueksi, mutta logiikka on aina täysin hölmö (Adler 1979, 108). Bunker on aina automaattisesti käymiensä kiistojen häviäjä - tästä huolehtivat omilla panoksillaan käsikirjoittajat, näyttelijä ja ohjaaja.

Kriitikkovastaanotto keskittyi Archien hahmoon: oliko noin ylitsepursuilevan peittelemätön kiihkoilu hauskaa, tyrmistyttävää, vaarallista vai vain huonoa makua osoittavaa (Adler 1979, xxiv-xxviii)? Kysymys nousi toden teolla esiin toisen tuotantokauden alussa, kun tunnettu kirjailija Laura Hobson kirjoitti pitkän artikkelin New York Timesiin. Siinä hän arvosteli kovin sanoin Perhe on pahin -sarjaa siitä, että se esitti Archie Bunkerin rakastettavana, suvait- 
semattomana kiihkoilijana ("loveable bigot"), jonka kautta sarja normalisoi rasismia ja ennakkoluuloja. ${ }^{3}$ Artikkelissaan Hobson identifioi Glorian ja Miken liberaaleiksi ja täten Archien näiden ideologiseksi vastapooliksi. Hän ei kuitenkaan lokeroinut Archieta konservatiiviksi (Hobson 1971, D1). Hobson ei ollut kuvailussaan poikkeus, sillä ylipäätään kriitikot eivät kutsuneet Archieta konservatiiviksi. Pamela Haynesin määritelmä Los Angeles Sentinel -lehdessä kävi silti lähellä: "Archie is a racist, a religious bigot, a card-carrying member of Spiro Agnew's Silent Majority" (sit. Adler 1979, 84). ${ }^{4}$

Archie ymmärrettiin ja esitettiin vastareaktiona sosiaaliselle ja kulttuuriselle muutokselle, mikä näkyi siinä, miten häneen viitattiin yleisesti vastakohtana Miken ja Glorian liberalismille. Tulkinta näkyi alusta asti muun muassa TV Guiden promootiomateriaalissa (Staiger 2000, 83-84). Vaikka Bunkeria ei siis kuvattu alun perin konservatiiviksi, hänet ymmärrettiin poliittisesti tietyn Nixonin valinneen konservatiiviryhmittymän edustajaksi (Adler 1979). Itse asiassa niin Nixon kuin National Review -lehden pitkäaikainen julkaisija William Rusherkin identifioivat Bunkerin ei konservatiivisuuden vaan tietyn konservatiivisen siiven edustajaksi (OVAL 1971, Frisk 2011). Edellä mainittu konservatiiviälykkö Buckley kirjoitti jälkeenpäin ohjelmaa muistellessaan, että ajatus Archie Bunkerista konservatiivina oli "ideologista huiputusta" (Buckley 2001, 58).

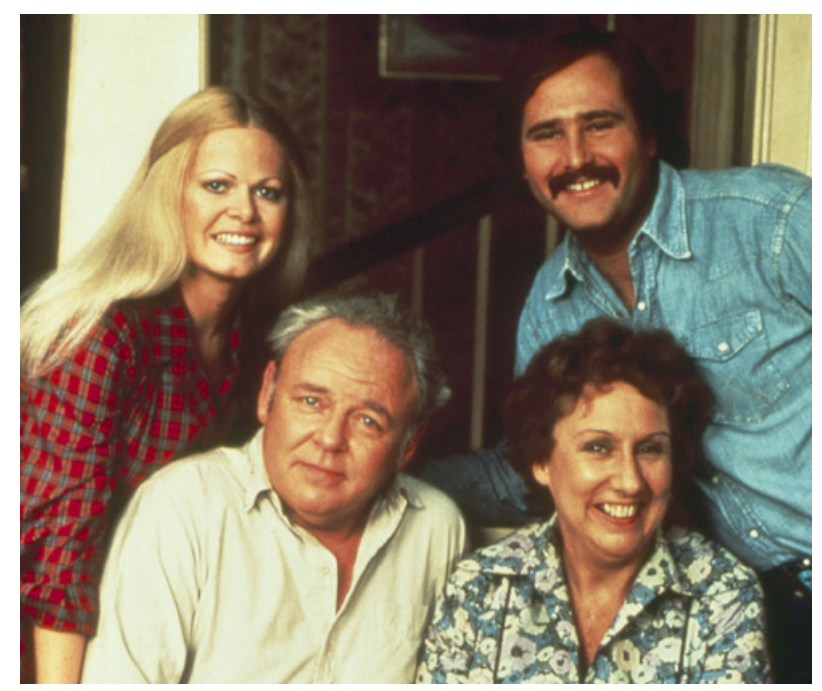

Bunkerien koti on sarjassa loputtomien poliittisten kiistojen areena, kun Archie (alhaalla vasemmalla) ottaa yhteen liberaalin tyttärensä Glorian (Sally Struthers, ylhäällä vasemmalla) ja vävynsä Miken (Rob Reiner, ylhäällä oikealla) kanssa. Edithin rooliksi jää toimia omatunnon äänenä. Kuva: Nelonen.

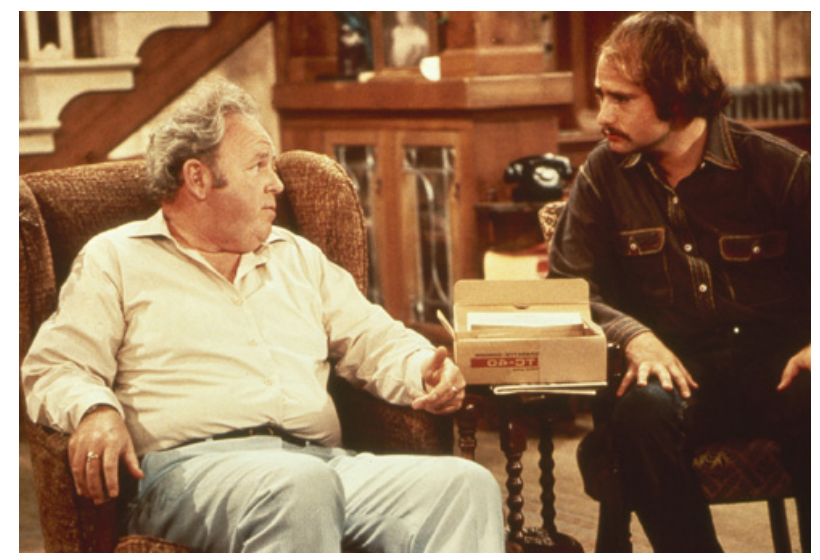

Archieta ei kuvattu kritiikeissä alun perin konservatiivina mutta hänet nähtiin ideologisena vastapoolina vävynsä Miken liberalismille. Kuva: Nelonen.
3 Hobsonin tunnettu romaani Gentleman's Agreement (1947) käsitteli antisemitismiä New Yorkissa ennen toista maailmansotaa.

4 Kansakunnalle osoitetussa televisiopuheessaan loppuvuonna 1969 Nixon puhutteli "hiljaista enemmistöä" ("the great silent majority"), jonka tukea hän pyysi pitkittyneen Vietnamin sodan ratkaisemiseksi (Nixon 1969). "Hiljainen enemmistö" muodostui ei vain republikaanien enemmistöstä vaan eksplisiittisesti konservatiivisesta enemmistöstä. 


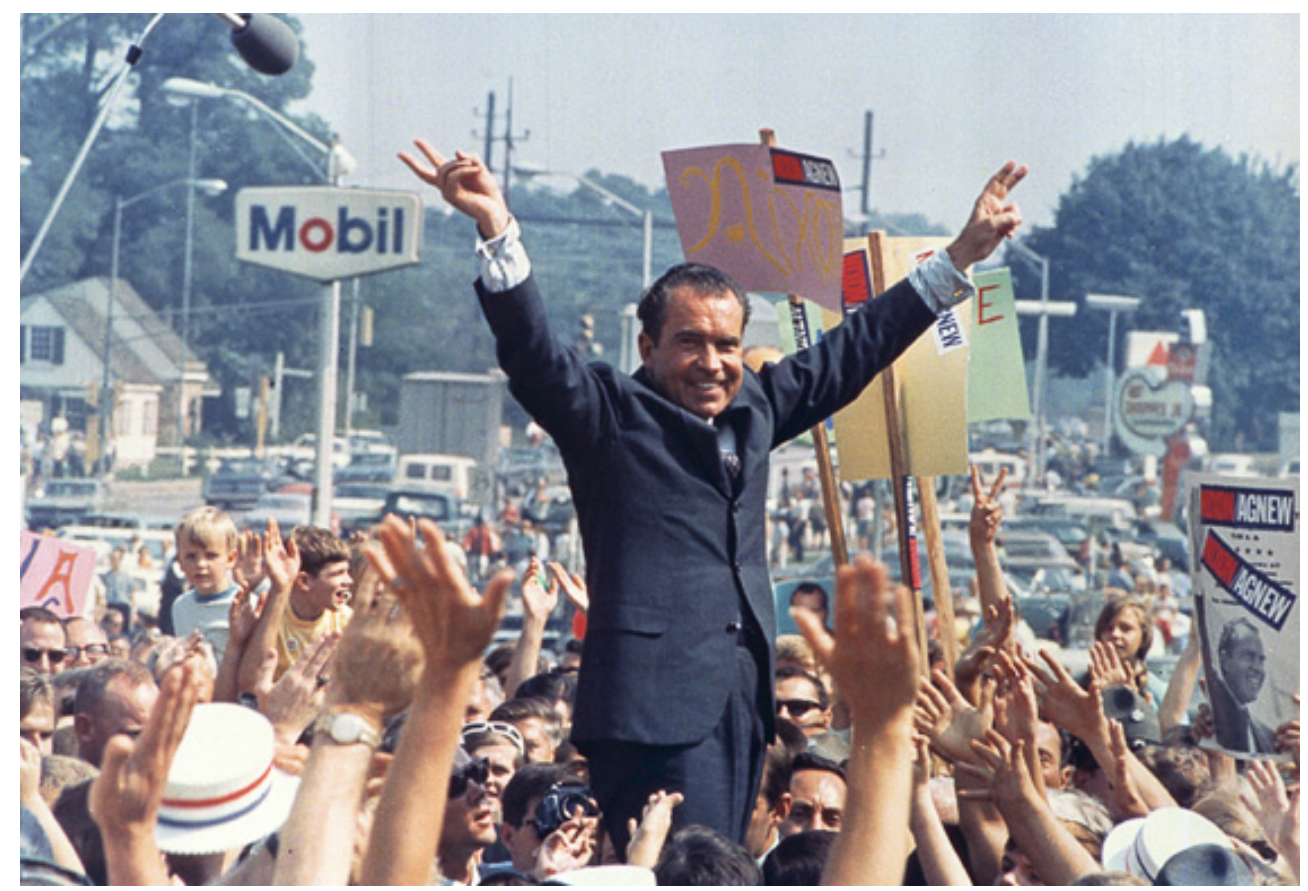

Archie Bunker ymmärrettiin poliittisesti Richard Nixonin presidentiksi valinneen konservatiiviryhmittymän edustajaksi. Kuvassa Nixon kampanjoi Philadelphiassa heinäkuussa 1968. Kuva: (C) Ollie Atkins, Wikimedia Commons, https://commons. wikimedia.org/wiki/File\%3ANIXONcampaigns.jpg.

Nykyään Wikipedia kutsuu Bunkeria kuitenkin konservatiiviksi, ja samoin tekee tunnetuin kirja Norman Learin tilannekomedioista (Campbell 2006, 13, 74) - itse asiassa viimeksi mainittu käyttää ilmausta "äärikonservatiivi" ("ultraconservative"). Myös Lear itse kutsuu Archieta konservatiiviksi taannoisessa omaelämäkerrassaan (Lear 2014, 248). Archien poliittisuus on kuitenkin monimutkaisempaa; sitä ei voida kiteyttää ajatukseen konservatiivisuudesta.

\section{Vasureita, värillisiä ja pervertikkoja}

Nyt, kun olen problematisoinut modernin amerikkalaisen konservatismin käsitteen ja selvittänyt Perhe on pahin -sarjan taustaa, positioin tarkemmin Archie Bunkerin konservatiivista ideologiaa suhteessa antikommunismiin, kansalaisoikeuksien vastustamiseen, perinteisiin seksuaalinormeihin ja laissez-faire-talousajatteluun (Phillips-Fein 2010). Suhteessa kolmeen ensiksi mainittuun Bunker oli anteeksipyytelemättömän konservatiivinen.

1970-luvulla antikommunismi ei ollut enää samanlainen konservatiiveja yhdistävä tekijä kuin 1950- ja 1960-luvuilla (McGirr 2001, 222). Kommunismi nähtiin nyt nimenomaan ulkoisena uhkana (Heale 1990, 191). Bunkerille tinkimätön antikommunismi on kuitenkin samaan aikaan tärkeä sisäpoliittinen kysymys ja ulkopoliittisen strategian ytimessä. Kun Mike ja Gloria sanovat Archielle, että ihmisveri on samaa riippumatta rodusta ja sosiaalisesta tai moraalisesta asemasta, tämä kumoaa väitteen kommaripropagandana ja Kremlin syöttämänä valheena (jakso: Archie Gives Blood, ensiesitys: 2/1971). Archielle liberalismi ja liberaalius ylipäätään ovat sosialismia - hän jopa kut- 
suu Franklin D. Rooseveltia ensimmäiseksi sosialismia kohti hivuttautuneeksi huippupoliitikoksi ("first creeping socialist"). CBS:n uutistoimittaja Walter Cronkite on hänelle puolestaan yksinkertaisesti kommunisti (Cousin Maude's Visit, 12/1971; The Man in the Street, 12/1971; The Locket, 12/1972). Eräässä jaksossa (Archie and the Lock-Up, 10/1971) Gloria ja Mike valmistautuvat sodanvastaiseen mielenosoitukseen. Archielle kyseessä on "vasurien protesti" ("pinko protest"), ja Glorian vastalauseista huolimatta hän lyttää koko asian "kommarien hevonkukkuna" ("commie crap-ola"). Mike tiivistää toisessa jaksossa (Gloria Poses in the Nude, 9/1971) Archien antikommunismin toteamalla, että tämä on viimeiset 30 vuotta etsinyt kommunisteja joka sängyn alta. 1970-luvulle tultaessa kansalaisoikeusliike oli enää varjo liikkeen aiemmista "sankarillisista päivistä" (nimitys, jota Joseph käyttää kansalaisoikeusliikkeen kaudesta 1950-luvulta 1960-luvun loppuun; Joseph 2006, 2-4). Jo saavutettujen lainsäädännöllisten voittojen toimeenpanosta tuli uusi kamppailu, varsinkin rotuerottelun päivittäisen toteutumisen torjumisesta (Carter 1996, 30-35). Esimerkiksi koulubussien avulla yritettiin kamppailla rotuerottelua vastaan kuljettamalla lapsi kaupunginosasta toiseen. Tavoitteena oli, että vaikka asuinalueet jakautuivat rotujen mukaan, kouluissa samaa eroa ei olisi (Tsesis 2008, 259). Tätä politiikkaa ei helpottanut, että Nixon pääsi Valkoiseen taloon strategialla, jossa rotukysymyksellä oli etnisten ryhmien eroja korostava rooli (Carter 1996, 30-35).

Jo sarjan ensimmäisessä jaksossa (Meet the Bunkers, 1/1971) Archie asettuu kansalaisoikeuksien vastaiselle kannalle. Mike pohtii köyhyyttä Yhdysvalloissa ja kysyy, ovatko mustat saaneet saman mahdollisuuden kuin valkoiset. Archie vastaa, että mustat ovat saaneet enemmän: miljoonat eivät marssineet ja protestoineet, että hän saisi työpaikan. Hän myös esittää, että koko kansalaisoikeusliike on tarpeeton. Eräässä toisessa jaksossa (Cousin Maude's Visit, 12/1971) Archie väittelee vaimonsa sukulaisen kanssa ja toteaa, että Eleanor Roosevelt "löysi" Yhdysvaltojen värilliset, jotka ovat siitä lähtien aiheuttaneet vain harmia.

Asuinalueissa näkynyt rotuerottelu on yksi sarjan toistuvista teemoista. Eräässä jaksossa (Lionel Moves into the Neighborhood, 3/1971) Archie juonittelee naapurustoon muuttamassa olevaa mustaa perhettä Jeffersoneja ${ }^{5}$ vastaan. Myöhemmin, kun perhe on jo muuttanut, Archie kerää edelleen nimiä uusien mustien naapurustoon muuttoa vastaan (The First and Last Supper, 4/1971; We're Having a Heat Wave, 9/1973). Archie yrittää verhota ennakkoluulonsa ja vastustuksensa etnisten ryhmien alueellista integraatiota kohtaan taloudellisten näkökohtien taakse. Ennakkoluulot tulevat esiin, kun hän harkitsee talonsa myyntiä: hän ei halua sen päätyvän mustalle kiinteistönvälittäjälle (The Blockbuster, 11/1971). Koulukuljetukset, joiden toivottiin olevan keino erottelun purkamiseksi, joutuvat niin ikään Archien kritiikin kohteeksi. Hän tulkitsee myös Nixonin vastustavan oikeuden päätöstä koulubussikäytännöstä ja ylistää tätä siitä (Archie and the Editorial, 9/1972). Koska Archie tyrmää ajatuksen kansalaisoikeusliikkeen tarpeellisuudesta ja vastustaa asuinpaikkaa koskevaa rotuerottelun lopettamista oikeusistuinten julistuksista huolimatta, voidaan päätellä, että Archie selvästi vastustaa kansalaisoikeusliikettä ylipäätään.

1960-luvulla seksuaalinormit olivat nopean muutoksen alaisina. Niin sanottu seksuaalinen vallankumous pohjasi pitkälti tieteen edistysaskelille, sosiaalisille pyrkimyksille ja muutoksille lainsäädännössä. 1970-luvun koittaessa nuoremmat ikäpolvet kyseenalaistivat aiemmat normit yksiavioisuudesta ja heteroseksuaalisesta perhemallista (Levine 2007, 7-9). Nämä muutokset
5 Jeffersonit olivat viisi tuotantokautta Perhe on pahin -sarjassa. Lear loi heille myös oman nimikkosarjansa The Jeffersons (CBS, 1975-1985). 


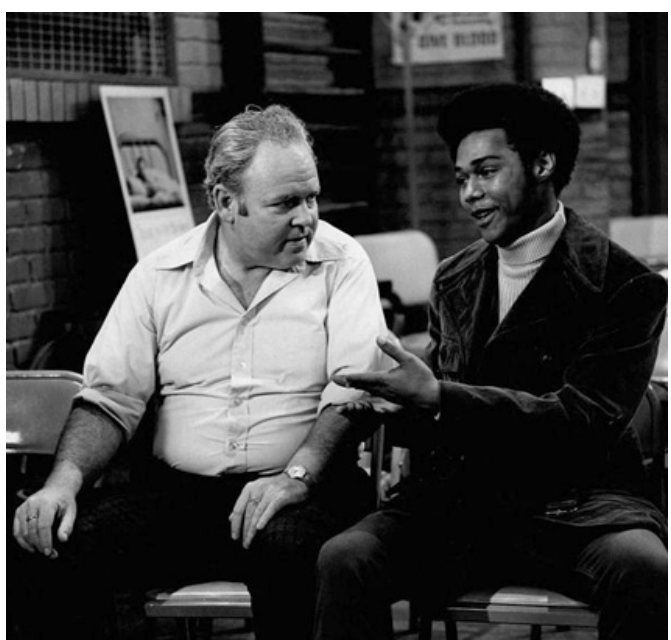

Asuinalueiden rotuerottelua kannattava Archie saa harmaita hiuksia, kun musta Lionel Jefferson (Mike Evans) muuttaa vanhempineen naapurustoon. Kuva: Wikimedia Commons, https://commons.wikimedia. org/wiki/File\%3AArchie_and_Lionel_ All_in_the_Family_1971.JPG.

eivät olleet Archien mielestä tervetulleita, vaan hänestä asiat olivat muuttuneet huonompaan suuntaan (Archie and the Editorial, 9/1972). Jo sarjan ensimmäinen jakso (Meet the Bunkers, 1/1971) sementoi Archien perinteisten seksuaalinormien kannattajaksi: Archie ja Edith yllättävät Glorian ja Miken matkalla makuuhuoneeseen ilmiselvin tarkoitusperin. Gloria vetoaa äitiinsä, että tämä selittäisi asian Archielle, sillä kyseessä on aivan normaali asia. Archie haastaa Glorian käsityksen normaalista kertomalla, että hän ja Edith eivät touhunneet mitään ennen hääyötä. Edith kuittaa miehensä periaatteellisen saarnan toteamalla, ettei silloinkaan tapahtunut mitään mainittavaa. ${ }^{6}$

Vaikka Gloria ja Mike ovat naimisissa, Archie ei pidä siitä, miten heidän seksuaalinen suhteensa on kaikkien nähtävillä kosketteluna ja kiusoitteluna. Hänen mielestään Glorian ja Miken koko sukupolvi ei tee muuta kuin ajattelee sukuelimillään (Gloria Has a Belly Full, /1971). Pahinta on kuitenkin avioliittoa edeltävä seksi, jonka Archie tuomitsee kategorisesti. Niinpä, kun Miken naimaton ystäväpariskunta haluaisi jäädä yökylään, Archie vastustaa asiaa siveettömänä. Hän toteaa, ettei ole ahdasmielinen mutta hänen sukupolvensa sentään kunnioitti "naiseutta" - ja tämän periaatteen rikkomista ja esiaviollista haureutta hän ei halua oman kattonsa alle (Mike's Hippie Friends Come to Visit, 2/1971). ${ }^{7}$ Avointen seksuaalisuuden osoitusten ja esiaviollisen seksin lisäksi Archie vastustaa homoseksuaalisuutta, rotujenvälistä seurustelua ja pornografiaa (Archie is Jealous, 3/1972; Judging Books by Covers, 2/1971; Lionel Steps Out, 10/1972; Writing the President, 1/1971).

Johtopäätöksenä voikin todeta, että Archie Bunker edustaa konservatiivia kolmessa Phillips-Feinin kategoriassa: hän on antikommunisti, vastustaa kansalaisoikeuksia ja puolustaa perinteisiä seksuaalinormeja. Kysymys talouspolitiikasta eli neljäs konservatismi-ideologian peruspilari osoittaa kuitenkin, että Archie Bunker on toisaalta problemaattinen konservatismin edustajana.

\section{Kypäräpäinen jäykkisduunari Bunker}

Bunker on valkoinen, työväenluokkainen ja kotoisin pohjoisen teollisuuskaupunkialueelta. Hän on demokraattien New Deal -koalition yhtä ydinryhmää. ${ }^{8}$ Sinikaulustyöläinen Archie on ylpeä ammattiliiton jäsen ja lakkoveteraani. Hän kertoo ylpeänä lakkomarsseistaan, joita hän vertaa Miken sodanvastaisiin mie-
6 Archie: "Used to be the daylight hours was reserved for the respectable things in life [...] in my day we were able to keep certain things in the proper surspective [sic]. Take keeping company for instance, your mother-in-law, when we was going it was two whole years we never - I never - I mean there was nothing! Absolutely nothing! Not 'til the wedding night."

Edith: "Yeah, and even then." (Meet the Bunkers, 1/1971.)

7 Archie: "I ain't narrow-minded, I just refuse to have any uncertified goings on under this roof [...] the point l'm trying to make is that my generation had a little respect for its womenhood [sic]" (Mike's Hippie Friends Come to Visit, 2/1971).

8 New Deal -koalitio toimi pohjana demokraattipuolueelle. Se muodostui 1930-luvulla Franklin Delano Rooseveltin idean pohjalta ammattiliittojen, etnisten vähemmistöjen, valkoisten etelävaltioiden rasistien ja älykköjen koalitioksi suuren laman aikana. Tämä herkkä koalitio kaatui lopullisesti 1960-luvulla, kun de-industrialisaatio, lähiöityminen, rotukonfliktit, taloudellinen stagnaatio ja Vietnamin sota erilaisine vaikutuksineen saivat aikaan sen, että osa demokraattien konservatiivisesta siivestä alkoi erityisesti etelävaltioissa liikkua republikaanien puolelle. Tämä oli kuitenkin tyypillisesti hidas, sukupolvenvaihdokseen kytkeytynyt muutos (Mason 2004, 6-11; Rae 1994, vii-viii). 
lenosoituksiin: kun hän marssi isänmaallisesti ammattiliiton puolesta, Mike marssii oman maansa hallitusta vastaan (Archie and the Lock-Up, 10/1971). On tärkeää ymmärtää, että Archie arvostaa suuresti New Dealin ammattiliittojen asemaa. Tämä asema perustui suurille jäsenmäärille, kollektiivisille työtaisteluille ja kurinalaisesti toteutetuille lakoille. Ammattiyhdistysliikeidentiteetti on keskeinen Archien hahmolle, ja hän on identiteetistään ylpeä (ks. The Saga of Cousin Oscar, 9/1971; The Man in the Street, 10/1971; Archie and the FBI, 1/1972). ${ }^{9}$

Archien asemasta liiton tukemana työnjohtajana huolimatta Bunkerit eivät ole immuuneja 1970-luvun taloudelliselle levottomuudelle - "tälle lamalle tai taantumalle, tai miksi sitä kutsutaankin", kuten eräässä jaksossa todetaan (The Insurance is Canceled, 11/1971). Taloudellinen epävarmuus tulee selkeimmin esiin siinä, että Archie ajaa viikonloppuisin ystävänsä taksia (Archie's Aching Back, 1/1971; Sammy's Visit, 2/1972; Archie and the Editorial, 9/1972; Archie's Fraud, 9/1972; The Taxi Caper, 12/1973). Myös Archien työnantaja Prendergast Tool and Die Company kärsii taloudellisesta taantumasta, mikä johtaa aina uusiin leikkauksiin (The Insurance is Canceled, 11/1971; Christmas Day at the Bunkers, 12/1971). "Yhtiö ilmoitti, että 20 prosenttia henkilöstöstä vähennetään, ja luulen, että minun osastoni tulee kärsimään suuresti", Archie kertoo. Hän valvoo koko yön, koska on huolissaan omasta työpaikastaan. Samalla hän muistelee 1930-luvun suuren laman vaikutusta isänsä elämään: "En koskaan unohda sitä, miten lama iski isääni. Ensin hän toi leivän pöytään kaikki ne vuodet, ja yhtäkkiä palkkasekkien tulo lakkasi [...]. Hän ei koskaan toipunut siitä, se mursi hänen sydämensä" (Archie s Worried about His Job, 3/1971). Archien taloudellinen asema perustuu New Dealin ammattiliittojen ja liberaalin talouspolitiikan yhdistelmälle, jota historioitsija Robert Self on luonnehtinut termillä "breadwinner liberalism" (Self 2013, 2, 14). Kyseisessä jaksossa Archie itse asiassa viittaa isäänsä termillä "bread-winner".

Archie on kroonisen huolestunut taloudesta, ja hän on hyvinvointimallin avoin kriitikko. Sarjan tunnuslaulussa Archie ylistää aikaa, jolloin hyvinvointimallia ei kaivattu ja kaikki tekivät oman osansa ("[we] didn't need no welfare state, [and] everybody pulled their weight"). Hyvinvointivaltion vastustuksesta huolimatta kyse ei ole vain nostalgiasta Herbert Hooverin aikoihin - aikaan ennen 1930-luvun suurta lamaa ja Rooseveltin New Deal -ohjelmia -, vaikka sarjan teemassa menneisiin aikoihin viitataankin. Kyse on paljon tätä monisyisemmästä ilmiöstä. Eräässä jaksossa paikallinen Progressive Partyn ehdokas kysyy Archielta, mikä hyvinvointivaltiossa sitten on hänestä väärin. Archie vastaa: "Kaikki." Kun ehdokas pyytää tarkentamaan, Archie paljastaa ajattelumallinsa: "Olen kyllästynyt sinun kaltaisiisi ihmisiin, jotka antavat minun kovalla työllä ansaitsemani rahat perheille, jotka eivät ole edes sukua, eivätkä edes voisi olla (ihonvärinsä takia)" (The Election Story, 10/1971). ${ }^{10}$ Tässä nousee esiin Archien kaksi keskeistä huolenaihetta: hänen oma taloudellinen turvansa ja hänen etnisiä vähemmistöjä kohtaan tuntemansa epäluulo, joka kytkeytyy kansalaisoikeuksien vastustamiseen.

Kritisoidessaan hyvinvointiohjelmia Archien retoriikassa toistuu ajatus, että hänen kovalla työllään ansaitsemansa rahat viedään hänen taskustaan (Judging Books by Covers, 2/1971; The Elevator Story, 1/1972). ${ }^{11}$ On syytä painottaa, että hän puhuu samalla tavalla myös hyväntekeväisyydestä: häntä huolestuttaa kaikki "ylimääräinen" rahanmeno. Kaukaisen sukulaisen kyläily ja Edithin kiertäville joululaulujen laulajille antamat rahat ovat askelia kohti "köyhäintaloa" (The Saga of Cousin Oscar, 9/1971; Christmas Day at the Bunkers, 12/1971). Hyvinvointimallin ja hyväntekeväisyyden kritisointi samalla
9 Archien hahmon luokkaulottuvuuksista ks. Cowie 2010; Collins 2012.

10 "I am sick and tired of people like you giving away my hard-earned money to a bunch of families who ain't even related to me, which they couldn't be related to me for complexionary [sic] reasons, you know what I mean" (The Election Story, 10/1971).

11 "[Being on welfare] is the same as picking my pocket" (Judging Books by Covers, 2/1971). 
diskurssilla on avain Archien ajatteluun: kritiikin syyt ovat henkilökohtaiseen talouteen liittyviä, eivät ideologisia. Ongelma ei siis olekaan hyvinvointimalli vaan se, kuka saa sen kautta rahaa (ks. esim. Success Story, 3/1971). Tätä tärkeää seikkaa on tarkasteltava seuraavaksi.

Archie siis kyllä laulaa Hooverin päivistä, mutta hänen poliittinen ajattelunsa perustuu laajemmin New Dealin käsityksille hallituksen vastuualueista. Vaikka Archie pitää hyvinvointimallia nollasummapelinä, jossa hän menettää rahaa, hän ei ole hyvinvointiohjelmia vastaan sinänsä. Kun Edith tuo vanhuksen Bunkerien kotiin, Archie valittaa siitä aiheutuvista kustannuksista todeten, että hallituksenhan se pitää miehestä huolehtia. Sekä vanhus että Mike selittävät Archielle, että sosiaaliturva on riittämätön, vanhukset vain "näkevät nälkää hitaammin", kuten Mike asian muotoilee. Archie vastaa piikikkäästi, että Miken pitäisi siis mennä töihin ja alkaa maksaa veroja - silloin hallituskin pystyisi parempaan (Edith Finds an Old Man, 9/1973). Archien kommentti kytkeytyy oleellisesti edellä mainittuun "breadwinner liberalism"ajatteluun. Tässä näkyy Archien ajattelun itsekeskeisyys; hän on huolissaan omasta taloudellisesta toimeentulostaan, ja huoleen liittyy hänen oma lähestyvä eläköitymisensä. Kuten edellä todetaan, Archie siis viittaa sarjassa isänsä kokemuksiin suuren laman aikana. Kun hän kyseisessä jaksossa saa myöhemmin tietää työpaikkansa olevan turvattu, hän toteaa, ettei kukaan työhaluinen näe nälkää Yhdysvalloissa (Archie is Worried about His Job, 3/1971). Archie näkee asiat vain omasta näkökulmastaan: hän on työpaikkansa pelastuttua jo unohtanut isänsä kohtalon.

Myös Archien asenne verotukseen korostaa hänen itsekeskeistä taloudellista ymmärtämystään ja käsitystään hallituksen vastuualueista. Hän ylistää Nixonin verohelpotuksia, kuten auton kulutusveron poistoa, ja kritisoi demokraattien veropolitiikkaa, kuten George McGovernin perintöveroehdotusta (The Man in the Street, 12/1971; Archie's Fraud, 9/1972). Tästä huolimatta hän on ylpeä ollessaan "tavallinen veronmaksaja", mikä liittyy hänen käsityksiinsä hallituksen vastuista (Writing the President, 1/1971; Success Story, 3/1971; The Election Story, 10/1971). Niinpä on mahdollista, että hän myöhemmin itsekeskeisyydessään tuomitsee Nixonin talouspolitiikan rivikansalaisia sorsivana (Archie and the Editorial, 9/1972). Hän jopa toteaa, että "Nixon is hurting me" ja vaatii rikkaita suosivien verotuksen porsaanreikien sulkemista (Archie's Fraud, 9/1972). Tässä tulee jälleen esiin Archien konservatiivisuuden ambivalenttius.

On selvää, että Archien talousajattelu ei noudata konservatiivien laissez-fairelinjaa. Hänen ajattelussaan yhdistyvät ammattiliittoidentiteetti ja egosentriset mutta New Dealin mukaiset käsitykset hyvinvoinnista ja veroajattelusta, jotka vastaavat Selfin "breadwinner liberalism" -mallia ja toisaalta Jefferson Cowien (2010) kuvausta työväenluokkaisesta kamppailusta. Hahmotelma Nixonin laajasta konservatiivisesta enemmistöstä on ehkäpä kaikkein ongelmallisin, kun sitä yritetään soveltaa kuvaan Archie Bunkerista konservatiivina. Koska työväenluokka oli sarjan kuvaamana aikana suurimpien sosiaalisten ja taloudellisten haasteiden edessä, Nixon keskittyi retoriikassaan kulttuurisiin arvoihin ja puhui vähemmän talouspolitiikasta. Tavoitteena oli luoda konservatiivinen enemmistö "kypäräpäisten duunarien" (hard-hats) varaan (Cowie 2010, 135-138). National Review'n julkaisija ja pitkän linjan konservatiivivaikuttaja William Rusher kutsui Nixonin linjaa keskittymiseksi "Archie Bunker -asioihin" eli juuri edellä mainittuihin traditionalistisiin ja antikommunistisiin juonteisiin talouspolitiikan kustannuksella (ks. Frisk 2011). Vaikka Archie Bunkeria kutsutaan siis nykyään konservatismin edustajaksi ja jopa ikoniksi, 


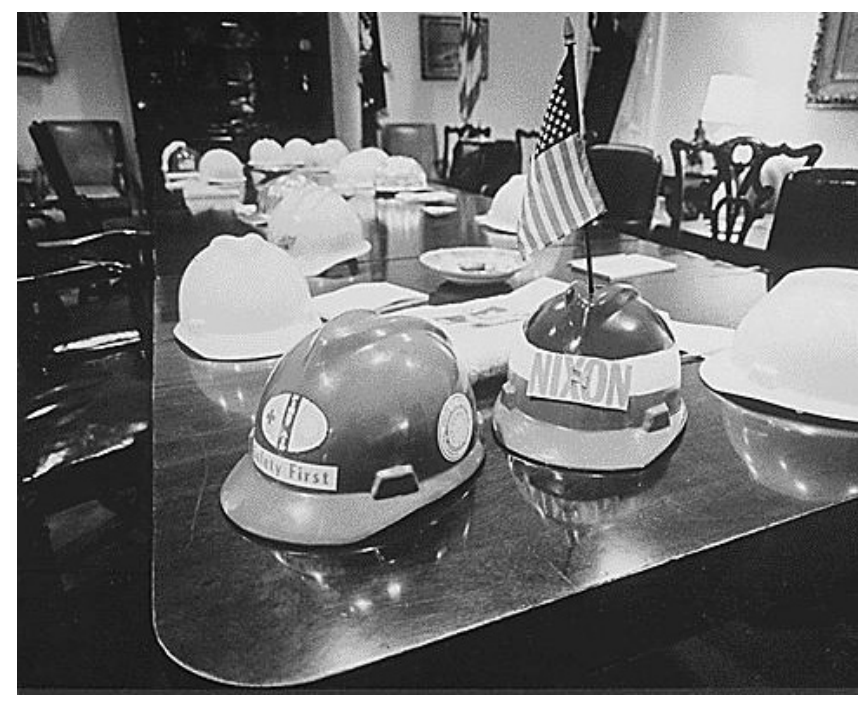

Nixonin tavoitteena oli luoda konservatiivinen enemmistö Archie Bunkerin kaltaisten "kypäräpäisten duunarien varaan". Kuva: Wikimedia Commons, https://commons.wikimedia.org/wiki/ File\%3AHard_hats_on_ Nixon_cabinet_table_ May_26\%2C_1970.jpg.

hän edusti todellisuudessa yhtä segmenttiä, josta Nixon yritti rakentaa uutta konservatiivista enemmistöä. Kuinka ollakaan, Nixon jopa viittasi Bunkeriin yksityisessä Valkoisen talon keskustelussa - ei konservatiivina tai republikaanina vaan "kypäräpäisenä jäykkisduunarina" (OVAL 1971). On oletettavaa, että hän ymmärsi, ettei Bunker sulattanut kaikkia hänen poliittisia linjauksiaan. Tavoitteena oli, että hän mahdollisimman monien amerikkalaistyöläisten tavoin sulattaisi niistä tarpeeksi monta.

\section{Lopuksi}

Vaikka Perhe on pahin -sarjan esitetään usein syntyneen 1960-luvun poliittisesta kuohunnasta, se syntyi yhtä lailla poliittis-ideologisesti riippumattomasta televisioteollisuuden sisäisestä katsojakilpailusta, joka suuntautui erityisesti haluttuihin kohderyhmiin. Viimeksi mainitut olivat mainostulojen ja täten kaupallisen televisiotuotannon perusta. Voidaan jopa väittää, että sarja ei kiinnostanut televisiojohtajia niinkään poliittisessa tai edes erityisen luovassa mielessä vaan haluttujen nuorten, koulutettujen, kaupunkilaisten kohderyhmien tavoittajana. 1970-luvulle tultaessa korporatiiviset intressit yksinkertaisesti vain vaativat uusia ohjelmia.

Carroll O'Connorin esittämä työläiskiivailija on epäilemättä yksi amerikkalaisen television ikimuistettavimmista hahmoista. Archie Bunker nousi yleisöjen tietoisuuteen ajankohtaisena poliittisena symbolina ja muotoutui myöhemmin konservatiivisuuden ikoniksi. Norman Lear ja O'Connor näkivät Bunkerin satiirisena versiona menneisyyteen katsovasta amerikkalaisuudesta ja esittivät hänet sellaisena kuin se näyttäytyi 1970-luvun nykyhetkessä: avoimen taantumuksellisena ja mennyttä haikailevana kiihkoilijana.

Hahmosta tuli joka tapauksessa paluuta tekevän konservatiivisuuden personifikaatio. Ideologisesti hahmo on paljon ambivalentimpi kuin yleensä esitetään. Hän on vankkumaton antikommunisti, perinteisten sukupuolinormien kannattaja ja kansalaisoikeuksien vastustaja. Tästä huolimatta hänen poliittisia mielipiteitään ei voi yksiselitteisesti kuvata republikaanisiksi tai konservatiivien linjauksia mukaileviksi. Varsinkin laissez-faire-talouspolitiikan suhteen hän on jopa erimielinen. Kuitenkin ajankohdan yhteiskunnallisessa 
kontekstissa hän on "hiljaisen enemmistön" jäsen, vaikka hän onkin kaikkea muuta kuin hiljaa mielipiteitään esittäessään. Tähän tosin vaikuttaa se, että kyseessä on televisio-ohjelma ja vielä komedia: mille nauraisimme, ellemme Bunkerin näkemyksille ja niiden ilmaisutavalle? Sarjan tekijät nimenomaan halusivat tehdä Bunkerista tietynlaisen komediallisen hahmon.

Archie Bunker edustaa sitä valkoista työväenluokkaa, johon Nixonin konservatiivisen enemmistön malli pohjautui. Nixonin ideana oli painottaa kulttuurisia ja sosiaalisia asioita talouspolitiikan sijaan. Bunker kuvastaa kysymystä ideologisista painotuksista ja ajattelumallia, jossa konservatiivisuuden edustajaksi voi nousta poliittisilta mielipiteiltään varsin ambivalentti hahmo. Nixonin retorisen strategian menestys kulminoitui myöhemmin Ronald Reaganin valinnassa Yhdysvaltojen presidentiksi vuonna 1980.

Vastaava ambivalenssi konservatismin opinkappaleita kohtaan on mahdollistanut Donald Trumpin nousun erittäin merkittäväksi tekijäksi republikaanisessa puolueessa. Konservatiivien periaatteista poikkeavia poliittisia ideoita tuetaan kovaäänisillä taantumuksellisilla mielipiteillä ennen kaikkea arvokonservatiivisissa kysymyksissä, joita Rusher kutsui Nixonin politiikassa "Archie Bunker -asioiksi". Trumpin vaalitilaisuuksissa nähtävät kyltit osoittavat lisäksi, että Trumpin kannattajat identifioituvat "hiljaiseen enemmistöön". Koomikko Larry Wilmore kysyikin Perhe on pahin -sarjan luojalta Learilta, tunteeko hän olevansa vastuussa siitä, että Archie Bunker - Donald Trump pyrkii nyt Yhdysvaltojen presidentiksi (The Nightly Show with Larry Wilmore, 2015). Wilmore oli tuskin tietoinen artikkelin alussa mainitusta graffitista New Yorkin metrossa 1970-luvun alussa, mutta hänen kysymyksensä on jälleen yksi osoitus Archie Bunkerin edelleen jatkuvasta kulttuurisesta merkityksestä konservatiivisena ikonina ja konservatismin komediallisena mutta yhtä kaikki yleisesti tunnistettuna edustajana.

\section{Tutkimuskirjallisuus}

Adler, Richard P. (toim.) (1979) All in the Family: A Critical Appraisal. Westport: Praeger Publishing.

Barnouw, Eric (1990) Tube of Plenty: The Evolution of American Television. 2. painos. New York: Oxford University Press.

Berkowitz, Edward D. (2006) Something Happened: A Political and Cultural Overview of the Seventies. New York: Columbia University Press.

Bowen, Michael (2011) The Roots of Modern Conservatism: Dewey, Taft, and the Battle for the Soul of the Republican Party. Chapel Hill: University of North Carolina Press.

Brinkley, Alan (1994) "The Problem of American Conservatism”. The American Historical Review vol. 99:2, 409-429.

Buckley, William F. (1955) “Our Mission Statement”. National Review vol. 1:1.

Buckley, William F. (2001) “The Laughter of Archie Bunker”. National Review vol. 53:14, 58.

Burns, Jennifer (2009) Goddess of the Market: Ayn Rand and the American Right. New York: Oxford University Press.

Campbell, Sean (2006) The Sitcoms of Norman Lear. Jefferson: McFarland \& Co.

Carter, Dan T. (1999) From George Wallace to Newt Gingrich: Race in the Conservative Counterrevolution 1963-1994. Baton Rouge: Louisiana State University Press.

Carter, Dan T. (2000) Politics of Rage: George Wallace, the Origins of the New Conservatism, and the Transformation of American Politics. 2. painos. Baton Rouge: Louisiana State University Press.

Castleman, Harry \& Walter J. Podrazik (2010) Watching TV: Six Decades of American Television. 2. painos. Syracuse: Syracuse University Press. 
Cowie, Jefferson \& Nick Salvatore (2008) "The Long Exception: Rethinking the Place of the New Deal in American History". International Labor and Working-Class History vol. 74, 1-32.

Cowie, Jefferson (2010) Stayin' Alive: The 1970s and the Last Days of the Working Class. New York: The New Press.

Durr, Kenneth D. (2003) Behind the Backlash: White Working-Class Politics in Baltimore, 1940-1980. Chapel Hill: University of North Carolina Press.

Edgerton, Gary R. (2007) The Columbia History of American Television. New York: Columbia University Press.

Fiske, John (1987) Television Culture. London: Routledge.

Frisk, David B. (2011) If Not Us, Who? William Rusher, National Review, and the Conservative Movement. Wilmington: ISI Books.

Gitlin, Todd (2000) Inside Prime Time. Tarkistettu painos. Berkeley: University of California Press. Greene, Doyle (2007) Politics and the American Television Comedy: A Critical Survey from I Love Lucy through South Park. Jefferson: McFarland \& Co.

Hamamoto, Darrell (1991) Nervous Laughter: Television Situation Comedy and Liberal Democratic Ideology. New York: Praeger Publishing.

Hartman, Andrew (2015) A War for the Soul of America: A History of the Culture Wars. Chicago: The University of Chicago Press.

Heale, M. J. (1990) American Anticommunism: Combating the Enemy Within, 1830-1970. Baltimore: Johns Hopkins University Press.

Hobson, Laura Z. (1971) "As I Listened to Archie Bunker Say 'Hebe"'. The New York Times September 12, D1.

Von Hodenberg, Christina (2015) Television's Moment: Sitcom Audiences and the Sixties Cultural Revolution. New York: Berghahn Books.

Joseph, Peniel E. (Ed.) (2006) The Black Power Movement: Rethinking the Civil Rights-Black Power Era. New York: Routledge.

Kirk, Russell (1981) “Libertarians: The Chirping Sectaries”. Modern Age vol. 25:4, 345-351.

Kirk, Russell (2001) The Conservative Mind: From Burke to Eliot. 7. painos. Washington D.C.: Regnery Publishing.

Kruse, Kevin M. (2007) White Flight: Atlanta and the Making of Modern Conservatism. Princeton: Princeton University Press.

Kruse, Kevin M. (2015) One Nation Under God: How Corporate America Invented Christian America. New York: Basic Books.

Lassiter, Matthew D. (2007) The Silent Majority: Suburban Politics in the Sunbelt South. Princeton: Princeton University Press.

Lear, Norman (2014) Even This I Get to Experience. New York: Penguin Press.

Levendusky, Matthew (2009) The Partisan Sort: How Liberals Became Democrats and Conservatives Became Republicans. Chicago: University of Chicago Press.

Levine, Elana (2007) Wallowing in Sex: The New Sexual Culture of 1970s American Television. Durham: Duke University Press.

Lewis, Penny (2013) Hardhats, Hippies, and Hawks: The Vietnam Antiwar Movement as Myth and Memory. Ithaca: ILR Press.

Marc, David (1996) Demographic Vistas: Television in American Culture. Tarkistettu painos. Philadelphia: University of Pennsylvania Press.

Mason, Robert (2004) Richard Nixon and the Quest for a New Majority. Chapel Hill: University of North Carolina Press.

McCrohan, Donna (1987) Archie \& Edith, Mike \& Gloria: The Tumultuous History of All in the Family. New York: Workman Publishing.

McGirr, Lisa (2015) Suburban Warriors: The Origins of the New American Right. Täydennetty painos. Princeton: Princeton University Press.

Mittell, Jason (2010) Television and American Culture. New York: Oxford University Press..

Moore, Barbara \& Marvin R. Bensman \& Jim van Dyke (2006) Prime-time Television: A Concise History. Westport: Praeger Publishing. 
Nash, George H. (1996) The Conservative Intellectual Movement in America since 1945. Wilmington: Intercollegiate Studies Institute.

Nixon, Richard (1969) Address to the Nation on the War in Vietnam. November 3. Gerhard Peters and John T. Woolley (toim.) The American Presidency Project, <http://www.presidency. ucsb.edu/ws/?pid=2303> (linkki tarkistettu 28.12.2015).

OVAL 498-5 (May 13, 1971) White House Tapes. Richard Nixon Presidential Library and Museum, Yorba Linda, California.

Ozersky, Josh (2003) Archie Bunker's America: TV in an Era of Change 1968-1978. Carbondale: Southern Illinois University Press.

Phillips, Kevin (1969) The Emerging Republican Majority. New York: Arlington House.

Phillips-Fein, Kim (2010) Invisible Hands: The Businessmen's Crusade Against the New Deal. New York: W.W. Norton \& Co.

Phillips-Fein, Kim (2011) "Conservatism: A State of the Field". Journal of American History vol. 98:3, 723-743.

Rae, Nicol C. (1994) Southern Democrats. New York: Oxford University Press.

Reinhard, David W. (1983) The Republican Right since 1945. Lexington: University Press of Kentucky.

Richardson, Heather Cox (2014) To Make Men Free: A History of the Republican Party. New York: Basic Books.

Rosa, Alfred F. \& Paul A. Eschholz (1972) “Bunkerisms: Archie's Suppository Remarks in All in the Family". The Journal of Popular Culture vol. 6:2, 271-278.

Schoenwald, Jonathan (2002) A Time for Choosing: The Rise of Modern American Conservatism. New York: Oxford University Press.

Schulman, Bruce \& Julian E. Zelizer (Eds.) (2008) Rightward Bound: Making America Conservative in the 1970s. Cambridge: Harvard University Press.

Self, Robert O. (2013) All in the Family: The Realignment of American Democracy Since the 1960s. New York: Hill \& Wang.

Staiger, Janet (2000) Blockbuster TV: Must-See Sitcoms in the Network Era. New York: NYU Press. Stein, Judith (2010) Pivotal Decade: How the United States Traded Factories for Finance in the Seventies. New Haven: Yale University Press.

Tsesis, Alexander (2008) We Shall Overcome: A History of Civil Rights and the Law. New Haven: Yale University Press. 